\title{
Viabilidade Econômico-Financeira para expansão da cafeicultura em Unaí, Minas Gerais
}

\author{
Douglas Fonseca dos SANTOS \\ Faculdade CNEC, Unaí, MG, Brasil
}

Gevair CAMPOS

Faculdade CNEC, Unaí, MG, Brasil

\author{
Received 11 December 19; Accepted 10 June 20. \\ Evaluation System: Double Blind Review \\ Editor: Jose Lindenberg Julião Xavier Filho, Dr. \\ ISSN: 2594-8040
}

To cite this paper: Santos, D. R., \& Campos, G. (2020). Viabilidade econômico-financeira para expansão da cafeicultura em Unaí, Minas Gerais. Journal of Perspectives in Management-JPM, 4, p. 84-100.

\begin{abstract}
Resumo
A cafeicultura é de extrema importância tanto na esfera econômica quanto na social com a geração de milhares de empregos e renda no Brasil. Minas Gerais é o maior produtor de café do Brasil. Dessa forma, a cafeicultura é uma atividade agregadora de valor econômico no estado. Nesse contexto, o objetivo deste estudo foi investigar quais fatores financeiros influencia a expansão da cafeicultura na Região Noroeste de Minas Gerais. Dessa forma, foram utilizadas algumas técnicas de indicadores para análise de projetos que buscam identificar a viabilidade de investimentos realizados nesta cultura. Em relação à metodologia utilizada, este trabalho teve como natureza a pesquisa documental, de campo, bibliográfica, exploratória, quantitativa-qualitativa. Buscou-se mensurar os gastos já ocorridos no empreendimento na safra 2016/2017, analisar o valor presente líquido, a taxa interna de retorno, o período de payback descontado e também o custo/benefício de um investimento realizado para melhor colher o café do chão, além de realizar estimativas de cenários futuros para a produtividade da empresa. Com os resultados obtidos, foi possível realizar a análise da viabilidade econômico-financeira do empreendimento sobre o investimento realizado, que se apresentou economicamente viável para região- noroeste de Minas Gerais.
\end{abstract}

Palavras-Chave: Cafeicultura; Viabilidade econômica; Investimento; Controle financeiro. 


\section{Introdução}

Historicamente o café foi importante no desenvolvimento socioeconômico para os países produtores dessa commodity, principalmente para o Brasil, onde essa commodity foi e continua sendo uma atividade de elevada relevância no desenvolvimento do país, além de ser uma das principais commodities agrícolas do mercado mundial.

O produto café, em geral, é transacionado em forma de commodity, ou seja, que atenda pelo menos três requisitos: padronização em um contexto de comércio internacional, possibilidade de entrega nas datas acordadas entre comprador e vendedor e possibilidade de armazenamento ou de venda em unidades padronizadas (Azevedo, 2001).

A cultura cafeeira requer a utilização de tecnologia intensiva em trabalho, o que a torna uma atividade geradora de emprego e renda. Produzido em países em desenvolvimento e consumido principalmente pelas nações desenvolvidas, o café tem a importante função de gerar divisas, contribuindo para a formação de uma balança comercial favorável ao desenvolvimento econômico (Viana, 2003).

É de extrema importância conhecer todos os custos que envolvem o processo de produção da organização, pois a realização de um controle financeiro adequado é fator essencial para manter a empresa, competindo com as concorrentes e ganhando mercado.

Sendo assim, a rentabilidade do produtor rural está diretamente relacionada com o bom planejamento de técnicas usadas para gerenciar e controlar os custos de produção visando otimizar seus processos internos para aumentar sua rentabilidade. Neste sentido a contabilidade de custos é, uma área necessária para o controle de todos os seus processos e custos; e tem como objetivo, além da maximização dos lucros, a melhoria contínua desses processos.

Em Minas Gerais, a cafeicultura tem importância para a geração de emprego e de renda, além da manutenção do homem no campo, dada a importância da cafeicultura para o estado. As informações relacionadas à instabilidade de preços e de produção são relevantes para o gerenciamento da empresa rural e para os cafeicultores que investem nessa atividade.

Segundo Kimura (1998), a administração agrícola se torna ainda mais complexa, uma vez que a oferta e a demanda são afetadas por fatores que não são controláveis diretamente pelo produtor, como o clima, a concorrência dos produtores, a demanda quando muito forte ou muito fraca, a conjuntura econômica, as políticas governamentais e as preferências dos consumidores que são muito voláteis.

Nesse contexto, pela relevância da cafeicultura na estrutura socioeconômica do estado e do país, pretende-se, com este estudo, responder a seguinte questão: Quais fatores financeiros influenciam a expansão da cafeicultura na Região Noroeste de Minas Gerais?

Verificando a importância do controle gerencial dos custos no agronegócio e a necessidade de um gerenciamento nas empresas rurais, partindo da questão problema, busca-se como objetivo geral analisar a viabilidade econômico-financeira de um empreendimento de produção e venda de café, para expansão da atividade na região Noroeste de Minas Gerais.

Para responder o objetivo geral deste estudo serão explanados os seguintes objetivos específicos, levantar os gastos ocorridos no empreendimento da safra 2016/2017; analisar o valor presente líquido, taxa interna de retorno, período de payback descontado do investimento, custo/benefício; e, estimar os gastos futuro até a safra de 2018/2019 e realizar analise de cenários.

Este trabalho tem como relevância em informar o cafeicultor sobre os retornos e riscos inerentes à cultura do café, tendo em vista a dificuldade de pequenos produtores rurais expandirem sua atuação, e aos benefícios econômicos em adotar sistemas produtivos que utilizam maiores níveis de insumos nas lavouras. Assim, pretende-se subsidiar o cafeicultor em suas tomadas de decisões para que ele obtenha o maior retorno e o menor risco sobre seu investimento na atividade cafeeira apresentando a viabilidade econômico-financeira da produção cafeeira na região Noroeste de Minas Gerais. 


\section{Cafeicultura no Brasil}

Sabendo-se da importância do agronegócio para o Brasil, com base no seu impacto no PIB, é possível observar então, a importância de seus ramos de culturas que são cultivados pelos produtores rurais, entre eles a cafeicultura. De acordo com a Companhia Nacional de Abastecimento (CONAB, 2016), a cafeicultura brasileira gerou uma produção de 51,37 milhões de sacas beneficiadas, apresentando um crescimento de 18,8\% em relação á safra anterior. A área total ficou em 2.223.464,1 milhões de hectares, com isso caracterizando uma redução de $1,1 \%$ em relação à área total da safra anterior.

De acordo com o mesmo autor, desse total, $272.786,5$ hectares que corresponde $(12,3 \%)$ estão em processo de formação e $1.950 .677,6$ hectares que corresponde com $(87,7 \%)$ estão em produção. E de acordo com a estimativa de área cultivada, a área plantada com a variedade café arábica no país soma um total de $1.759 .730,1$ hectares, que corresponde com $79,13 \%$ das áreas existente com lavouras de café.

Ainda segundo a CONAB, Minas Gerais é o estado que concentra maior área com a espécie do café arábica, a área corresponde com 1.184 .384 hectare é considerado com $67,3 \%$ da área ocupada com a variedade de café arábica em âmbito de participação nacional, para a variedade do café conilon o levantamento feito pela CONAB (2016), é de 424.773 hectares em produção, e apresentando 39.011 hectares em formação dessa variedade.

Analisando a estimativa de produtividade da CONAB (2016) considerando as duas variedades de café (arábica e conilon), ficou estimada uma produtividade média de 26,33 sacas de café por hectares comparado a safra passada, apresenta um ganho de 17,1\% com exceção dos estados de Bahia, Espírito Santo, Paraná e Rondônia os demais estados apresentam um crescimento relativo.

Na safra 2016 em relação a 2015 a área em produção sofre um acréscimo de 1,5\%, em relação à produtividade de 2016 apresenta um acréscimo de 17,1\%, esse aumento como já relatado pode ser influenciado a bienalidade positiva da produtividade e as condições climáticas, com o manejo adequado das lavouras as formas de fazer os tratamentos do café pode influenciar positivamente na produtividade e na qualidade do café.

Embora se iniciou o ano de 2016 com altos índices de exportações o setor do agronegócio encerrou o ano com taxas de embarques para exportação menores que as registradas em 2015 , de acordo com o CEPEA - Centro de Estudos Avançados em Economia Aplicada da Esalq/USP, (2016a), o que favoreceu positivamente para a valorização do real frente ao dólar, em decorrência do clima adverso ouve queda da produção agrícola nacional.

Com o comparativo de janeiro a dezembro do ano de 2016, em relação a 2015 no mesmo período, ouve uma queda no volume exportado pelo agronegócio brasileiro de $2,6 \%$, de acordo com (CEPEA, 2016b) o volume exportado no mês de dezembro de 2016 foi de $41 \%$ inferior ao que foi exportado no mesmo período de 2015.

Como ouve queda nos preços dos dólares recebidos pelos exportadores de $1,8 \%$ favorecendo para que houvesse um recuo no faturamento em dólar do setor de $3,6 \%$, sendo fechado em US\$ 86 bilhões de dólares, apresentando uma queda expressiva de $21 \%$, seguido pelo motivo da desvalorização da taxa de câmbio real do agronegócio em 17,6\% de acordo com os índices de exportações 2016, houve uma redução no índice de atratividade do agronegócio de 19\% no mesmo período (CEPEA, 2016b).

As vendas externas do agronegócio nacional foram apresentadas em 2016 com um crescimento de janeiro a março, logo em seguida havendo um recuo até se encerrar o ano. O Índice de taxa de câmbio efetiva real apresentada do agronegócio segundo Cepea (2016) apresentou a valorização com um elevado grau do real frente às moedas dos principais parceiros do agronegócio brasileiro em 2016, ao realizar um comparativo entre dezembro de 2016 com dezembro de 2015, pode se notar que o aumento foi de $34,5 \%$.

Como o ano de 2016 é ano de "safra cheia", como dizem os cafeicultores, o Brasil conseguiu exportar mais de 34 milhões de sacas de café, aliado com uma receita cambial de US\$ 
5,4 bilhões, chegando a esse resultado com a melhor série histórica do café arábica, segundo o Conselho dos Exportadores de Café do Brasil Cecafé, (2016).

No ano de 2016 o café teve uma participação no agronegócio de 6,4\% no segmento, mas em nível geral a participação nas exportações a representatividade que essa commodity teve foi $2,9 \%$, conseguindo manter o bom desempenho no comercio exportado do país (CECAFÉ, 2016). Dentre os principais importadores de café brasileiro podemos apresentar como principais: Estados Unidos, Alemanha, Itália, Japão e Bélgica (MAPA, 2016).

No Brasil, são produzidos o café arábica e o conilon (ou robusta), de acordo com o MAPA (2016), o café arábica é destinado ao consumidor que deseja degustar um produto mais fino, de maior qualidade. Já o café conilon é possuidor de um maior teor de cafeína e utilizado na fabricação de cafés solúveis.

\subsection{Cafeicultura em Minas Gerais}

O dia a dia da maioria dos brasileiros só começa depois de uma boa xícara de café pela manhã, uma rotina indispensável para muitos, o consumo da bebida apresentou um acréscimo de 3,48\% entre novembro de 2015 e fevereiro de 2016, de acordo com a Associação Brasileira da Indústria de Café - ABIC (2016). Uma ótima notícia para os consumidores dessa bebida é que o maior estado produtor deste grão no Brasil, Minas Gerais, registrou em 2016 um volume recorde de 30,7 milhões de sacas beneficiadas. Esse número apresenta um acréscimo de 37,8\% em comparação à safra anterior, e equivalente a $60 \%$ de toda a produção nacional, que em 2016 ficou em 51,37 milhões de sacas beneficiadas de acordo com a CONAB (2016).

Estes dados apresentados fazem parte do quarto e último levantamento anual da safra CONAB, apresentado em dezembro, logo após ter passado todo o período de pós-colheita. Em Minas Gerais a área total de café (em produção) ultrapassou um milhão de hectares, ficando em 1.009.481,0 milhões de hectares, apresentado um acréscimo em relação à safra de 2015 de 4,2\%.

Com base no balanço social de 2016, divulgado pela EPAMIG (2016), a commodity café constitui uma importante linha de pesquisa e desenvolvimento da EPAMIG, as ações desempenhadas contemplam toda a cadeia produtiva do café, desde a seleção da variedade mais adequada para se compactar ao solo, no clima da região escolhida, pois tudo isso influencia na produtividade, principalmente variedades resistentes às pragas aonde entra a redução de custos, e manter o planejamento e os cuidados certos pós-colheita, que também são influenciadores na qualidade da bebida que chega ao consumidor final.

Para o café arábica em Minas Gerais, a área em produção de 2016 ficou em 996.749,0 mil hectares, apresentando um índice de 4,3\% superior a 2015, a produtividade dessa variedade também apresentou um acréscimo, em 2016 a produtividade ficou em 30,53 sacas de café arábica por hectares, um aumento em relação produtividade passada de $32,8 \%$.

A área em produção do café conilon em Minas Gerais em 2016 ficou em 12.732,0 mil hectares, apresentando um índice de $(4,8 \%)$ inferior em relação a 2015 , a produtividade dessa variedade também apresentou queda, em 2016 a produtividade ficou em 23,26 sacas de café conilon por hectares, uma redução em relação à safra de 2015 de $(7,7 \%)$.

Os dados que serão apresentados fazem parte do segundo levantamento anual da safra CONAB apresentados em maio, no período de pré-colheita. No estado de Minas Gerais a área total de café em produção segundo a estimativa de 2017 é 955.086,0 mil hectares apresentando uma redução ao ano de 2016 de (4,2\%), a área em formação em 2016 se apresentava com 187.635,0 mil hectares para 2017 havendo um aumento de 34,9\%, no Triângulo, Alto Paranaíba e Noroeste para safra de 2017 está estimada em 169.702,0 mil hectares apresentando uma redução em relação a 2016 de (7,3\%) (CONAB, 2017).

De acordo com a Conab, para safra de 2017, em Minas Gerais, está estimada uma produção de 25,7 milhões de sacas de $60 \mathrm{~kg}$ de café beneficiadas. Estima-se uma produtividade média de 24,35 sacas por hectares, havendo uma redução de 7,5\% comparando a safra 2016.

Os produtores adquirindo uma melhor forma de manejo de suas lavouras, buscando pacotes tecnológicos mais desenvolvidos, têm levado ao longo dos anos na diminuição da diferença que 
existe entre as produtividades do ciclo positivo e negativo, como pode ser analisado entre 2001 e a estimativa de 2017 de acordo com a CONAB (2017).

Gráfico 1 - Produtividade de café total (arábica e conilon) no Brasil.

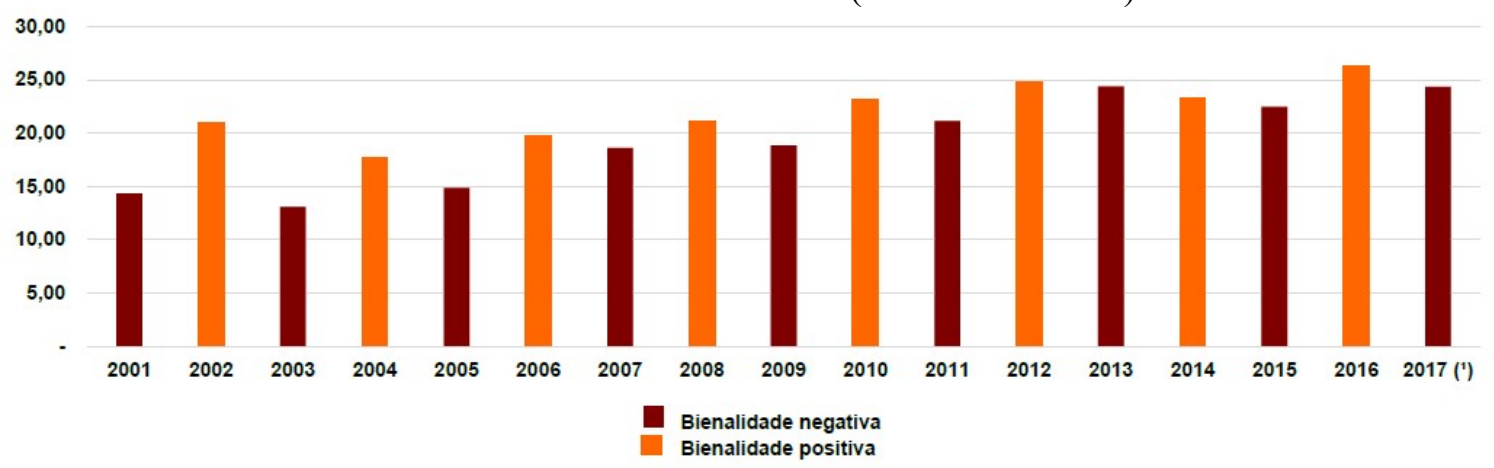

Fonte: CONAB (2017).

De acordo com a Conab (2017), o ciclo bienal negativo consiste na alteração de um ano com boa florada sendo bem intensa e seguida por outro ano em que a florada não se apresenta intensa, por ser uma forma característica natural da planta, que é ocasionada pelo esgotamento da planta pela sua alta produção, mas com o ano sendo negativo a planta estará se recuperando para produzir melhor na próxima safra.

\subsection{Receitas e Classificação de Gastos}

Na visão de Sá (2000), a receita é a entrada de recursos financeiros na empresa, ou seja, são a recuperação do investimento feito pela organização, as unidades acabadas e comercializadas, gerando receitas pelo seu preço unitário de determinado produto e multiplicado por suas respectivas quantidades. Já os custos para Crepaldi (2002), trata-se de uma despesa que é realizada a fim de obter um rendimento no final do processo, estabelecendo assim um preço para seu produto ou serviço que esteja sendo oferecido, e deve-se ter conhecimento sobre qual é seu custo total e seu custo unitário por unidade.

De acordo com os autores Bruni e Famá (2003), pela ótica financeira e empresarial defendem que existem duas maneiras para realização de um investimento em um ambiente. A primeira refere-se a investimento financeiro, que é caracterizado pela compra de títulos e valores imobiliários. Essa forma de investimento é caracterizada por se ter um retorno mais rápido do valor que é investido (maior liquidez). A segunda maneira para realização do investimento é o de capital, que é caracterizado por aquisição de novas máquinas ou até mesmo a reforma de sua planta industrial. Segundo os mesmos autores essa forma de investimento é denominada de projeto de investimento.

Para Padoveze (2010) os custos (gastos), são investimentos que são necessários para a concepção de bens e serviços para a empresa, gastos relacionados ao produto que a empresa espera ter. Portanto, podemos dizer que os custos são gastos relacionados ao produto e que são ativados quando os produtos a que se destinam são gerados. De modo geral, são os gastos ligados à área de produção da empresa. Para o mesmo autor, as despesas são gastos requeridos para vender e enviar os seus produtos que estejam relacionados às áreas administrativas e comerciais.

Os pagamentos são classificados como atos financeiros referentes a pagamentos de uma dívida, um produto, um direito ou um bem que foi adquirido (Padoveze, 2010). O mesmo autor destaca que perdas são fatos que são ocorridos devido a situações excepcionais que fogem da normalidade das operações da empresa, não fazendo parte dos custos de produção de produtos ou serviços. Quanto aos prejuízos, o mesmo autor explica que é resultante negativamente da apuração de resultado de um determinado período, no qual as despesas suplantam as receitas do período. 


\subsection{Classificação de Custos}

De acordo com Crepaldi (2002), os custos podem ser classificados da seguinte maneira: custos fixos e custos variáveis.

Quanto aos custos fixos, estes se mantêm constantes e não variam proporcionalmente ao volume produzido na produção. Por exemplo, aluguel, seguro da fábrica. Os custos fixos são fixos dentro de determinada faixa no setor de produção, mas em geral, esses custos não são eternamente fixos, com isso pode ocorrer de sofrer variação em função de grandes oscilações no volume produzido.

Custos variáveis: esses variam proporcionalmente ao volume que é produzido. Exemplo: matéria-prima. Se caso não houver quantidade produzida, o custo variável não se apresentará, pois será nulo. Os custos variáveis aumentam na medida em que aumenta a produção.

Para Crepaldi (2011), há a ocorrência dos custos diretos e indiretos. Os custos diretos estão diretamente (sem rateio) ligados aos produtos agrícolas, bastando apenas existir uma medida de consumo a ser utilizada constantemente (quilos, horas de mão de obra dos colaboradores ou das máquinas etc.). De maneira geral, identificam os produtos agrícolas e podem variar proporcionalmente à quantidade que espera a ser produzida. Podemos dar como exemplo, a depreciação de equipamentos agrícolas, quando é utilizado para produzir ou realizar manutenção em apenas um tipo de produto.

Já os custos indiretos para serem incorporados aos produtos agrícolas necessita utilizar algum tipo de critério de rateio. A separação dos custos diretos e indiretos, além de sua natureza, é levada em consideração a relevância e o grau de dificuldade de medição. Podemos dar como exemplo, o gasto com energia elétrica (força) e também por sua natureza, como um custo direto, pelas dificuldades na medição do consumo por produto agrícola e também ao fator que o valor obtido através dos rateios realizados, em geral, pouco difere daquele que seria encontrado com uma medição rigorosa, e quase sempre é considerado como custo indireto. Como pode ser estabelecido o custo indireto depende de cálculos, rateios ou estimativas para serem apropriados.

Crepaldi (2011, p. 103) entende que o rateio:

[...] representa a alocação de custos indiretos à produção, segundo critérios racionais. Exemplo: depreciação de máquinas agrícolas rateada segundo o tempo de utilização (horamáquina) por produto etc. Contudo, dada a dificuldade de fixação de critérios de rateio, tais alocações carregam consigo certo grau de arbitrariedade.

A simples mudança de um critério de rateio pode afetar todo o custo de produção e com isso consequentemente afetará o resultado final da empresa rural, podemos destacar como importância do critério de rateio por está intimamente relacionada a manutenção ou a uniformidade de sua aplicação.

\section{Análise de Viabilidade Econômico-Financeira}

Segundo Samanez (2010), existem várias técnicas e métodos que são comumente utilizados na análise e na avaliação do processo decisório, que busca estabelecer parâmetros da sua viabilidade e que possa permitir a análise da rentabilidade do investimento realizado. Os indicadores econômicos que serão utilizados neste presente estudo são descritas a seguir, segundo Samanez (2010).

\subsection{Valor Presente Líquido (VPL)}

O método do valor presente líquido (VPL) mede os valores presentes dos fluxos de caixas que são gerados pelos projetos ao longo da sua vida útil, expressa por: 


$$
V P L=-I+\sum_{t=1}^{n} \frac{F C_{t}}{(1+K)^{t}}
$$

Critério de decisão: se VPL > 0, o projeto é economicamente viável. Em que FCt representa o fluxo de caixa no t-ésimo período, I apresenta o investimento inicial, $\mathrm{K}$ é o custo do capital, e o símbolo $\sum$ representa "Somatório", indica que deve ser realizado a soma da 1 até a data n que são descontados no período inicial.

\subsection{Taxa Interna de Retorno (TIR)}

TIR é a taxa de retorno que é esperada do investimento que foi realizado, este método não tem como finalidade apresentar a avaliação da rentabilidade, sua finalidade é encontrar uma taxa intrínseca de rendimento do investimento, expressa por:

$$
\mathrm{VPL}=-\mathrm{I}+\sum_{\mathrm{t}=1}^{\mathrm{n}} \frac{\mathrm{FC}_{\mathrm{t}}}{\left(1+\mathrm{i}^{*}\right)^{\mathrm{t}}}=0
$$

Critério De decisão: se $i^{*}>\mathbf{K}$, o projeto é economicamente viável. Em que FCt é o fluxo de caixa, I é a taxa, e T representa o tempo.

\subsection{Payback descontado (PBD)}

O payback descontado apresenta o período de tempo que será necessário para recuperação do capital investido inicialmente e remunerada considerando a taxa de desconto, expresso por:

$$
I=\sum_{t=1}^{T} \frac{F_{C}}{(1+K)^{t}}
$$

Em que I apresenta o investimento inicial; FCt, representa o fluxo de caixa que é utilizado no período $\mathrm{T}$ e $\mathrm{K}$ apresenta o custo do capital.

\subsection{Custo/Benefício (C/B)}

Custo/Benefício é um indicador que é resultado do valor atual dos benefícios pelo valor dos custos que foram inseridos no projeto, ainda ressalta que inclui o investimento inicial. É possível descobrir a viabilidade quando o valor do índice for superior a 1 . $O$ índice pode ser expresso da seguinte forma:

$$
B / C=\frac{\sum_{t=0}^{n} \frac{b_{t}}{(1+K)^{t}}}{\sum_{t=0}^{n} \frac{c_{t}}{(1+K)^{t}}}
$$

Em que: $\mathrm{B} / \mathrm{C}=$ índice custo-benefício; $\mathrm{Bt}$, benefícios do período $\mathrm{t}$; $\mathrm{Ct}$, custos do período $\mathrm{t}$; $\mathrm{n}$, horizonte de planejamento; $\mathrm{K}$ é o custo do capital. 


\section{Método}

Para melhor compreender as técnicas e os métodos utilizados nesta pesquisa, que tem como objetivo apresentar a viabilidade econômico-financeira e quais os fatores que influencia a expansão da cafeicultura na região Noroeste de Minas Gerais, é imprescindível apresentar e definir o conceito que se tem por pesquisa.

Minayo (2011, p. 16) argumenta que "entendemos por pesquisa a atividade básica da ciência na sua indagação e construção da realidade”. Diante do que está exposto podemos dizer que é a produção do conhecimento, é uma contribuição para o avanço do desenvolvimento social como também da ciência, pois permite a descoberta de novos conhecimentos e por compreensão cientifica da temática estudada. $\mathrm{O}$ conhecimento científico que na maioria das vezes não tem sua verdade absoluta, o resultado de toda uma metodologia científica pela qual levanta várias hipóteses básicas de conceitos científicos, e são submetidas a rigorosas análises e verificações para que o estudo realizado tenha validações.

De tal forma, no que concerne o delineamento da pesquisa e partindo-se da proposta do estudo, esta pesquisa será considerada as abordagens: pesquisa documental, de campo, bibliográfica, exploratória, quantitativa-qualitativa.

Partindo de um pressuposto de necessidade de verificações em fontes secundárias, onde pode abranger todo um conhecimento acerca do fato não perceptível, já tornada pública acerca do tema abordado, por meio de publicações, jornais, revistas, livros atualizados, pesquisas e monografias acerca do tema, até mesmo por meio de comunicações orais: rádio, filmes e televisão. Sua principal finalidade e poder colocar o pesquisador em contato direto com o que está sendo analisado (Marconi \& Lakatos, 2011).

A pesquisa de campo de acordo com Marconi e Lakatos (2011) é aquela que é utilizada com a finalidade de conseguir informações ou conhecimentos a respeito de um problema que está sendo investigado ou de uma hipótese que se queira comprovar um fato ocorrido.

Segundo o mesmo autor a pesquisa exploratória caracteriza-se como investigações com o objetivo de formulações de questões ou de um problema a se desenvolver hipóteses a fim de aumentar a familiaridade com o pesquisador acerca do problema que está sendo observado.

Dessa forma, suas informações não serão coletadas de uma única maneira, mais em diferentes modos, com o objetivo de coletar dados que representem o máximo da realidade estudada, podendo assim chegar ao máximo, próximo dos resultados reais, e reduzir margens de erros nas conclusões.

O trabalho a ser estudado foi realizado no município de Unaí - Minas Gerais, em uma fazenda localizada a $(78,2 \mathrm{Km})$ de Unaí, com uma área de 91 hectares de planta de café. Na região não possui muitas fazendas cultivadas com essa cultura, onde os mais presentes encontrados são lavouras de cereais como milho, soja, sorgo, feijão, onde o agronegócio é muito forte na região. A escolha da propriedade se deu por conveniência.

Em razão dos objetivos específicos propostos deste estudo e do seu delineamento, partindo com o intuito de coletar o maior número de informações precisas para levantamento dos dados será utilizado o tipo de entrevista semiestruturadas com o gerente administrativo e o diretor financeiro da organização, para que dessa forma, possa melhor compreender a realidade vivida. Vale ressaltar que todos os dados coletados foram fornecidos pelos gestores que fazem todo o controle financeiro da organização, através dos relatórios contábeis do período estudado.

As fontes de documentos para a pesquisa documental caracterizam-se por sua diversidade e dispersão, podendo ser tabelas estatísticas, como gráficos, relatório da empresa e documentos informativos sobre dados. Nesta pesquisa, as fontes de dados que serão consultadas serão relatórios como planilhas de custos e relatórios e dentre outros que serão disponibilizados pela organização.

Contudo, justifica-se a escolha da organização e dos participantes do estudo a ser realizado por alguns fatores significantes, podemos dar como exemplo, questões sobre a gestão financeira da organização, todos os custos que envolvem diretamente a organização e indiretamente, e todo o planejamento de investimentos a serem realizados, para que não ocorra imprevistos no desenvolver de todo o processo de expansão. 
A utilização de técnicas como VPL, TIR, Payback e Análise Custo/Benefício veem sendo amplamente utilizada para analisar viabilidade e rentabilidade de investimentos, inclusive no agronegócio. E uma forma de expandir uma atividade, se justifica em função da rentabilidade que ela irá trazer ao negócio, assim, se justificando a realização deste estudo.

\section{Análise dos Resultados}

Os custos de produção da atividade cafeeira da safra de 2016/2017 a serem analisados possuem uma produtividade estimada entre 40 a 45 sacas de café por hectare, apresentando uma média anual de 42 sacas. Como pode ser observado na Tabela 1 são apresentados os custos que envolvem a produção cafeeira.

Tabela 1: Composição dos custos por setor que envolve a produção Cafeeira.

\begin{tabular}{c|c|c}
\hline Descrição & Custo/ha & Valor total \\
\hline Fertilizantes & $\mathrm{R} \$ 3.450,00$ & $\mathrm{R} \$ 313.950,00$ \\
\hline Agrotóxicos & $\mathrm{R} \$ 1.400,00$ & $\mathrm{R} \$ 127.400,00$ \\
\hline Despesas Administrativas & $\mathrm{R} \$ 2.500,00$ & $\mathrm{R} \$ 227.500,00$ \\
\hline Mão de Obra & $\mathrm{R} \$ 3.200,00$ & $\mathrm{R} \$ 291.200,00$ \\
\hline Fornecedores de peças & $\mathrm{R} \$ 1.350,00$ & $\mathrm{R} \$ 122.850,00$ \\
\hline Despesas Operacionais & $\mathrm{R} \$ 3.280,00$ & $\mathrm{R} \$ 298.480,00$ \\
\hline Custo Total & $\mathrm{R} \$ 15.180,00$ & $\mathrm{R} \$ 1.381 .380,00$
\end{tabular}

Fonte: Dados da pesquisa (2020)

A administração correta proporciona um maior entendimento dos custos e fatores importantes nas tomadas de decisões, por saber todos os custos e despesas que estão envolvidas na cultura, além de proporcionar maior entendimento sobre qual dos custos está muito além do normal, para fazer cortes de gastos desnecessários sem dispensar colaboradores.

Como pode ser observado na Figura 1, observa-se que os fertilizantes representam $23 \%$ dos custos da lavoura, seguidos pelos Agrotóxicos com (9\%); os custos relacionados às despesas administrativas representam (16\%); os custos com mão de obra representa $(21 \%)$ dos custos da lavoura, custo apresentado relativamente alto pelos tratos realizados na lavoura devido a manutenção na lavoura no qual foram contratado mão de obra de terceiros para ser efetuado com maior rapidez; os custos com fornecedores de peças e fornecimento de demais materiais representa $(9 \%)$; as despesas operacionais que compõe os serviços realizados na fazenda com a colheita mecanizada, serviço de recolhimento do café de varreção entre outros, representam $(22 \%)$ dos custos da produção cafeeira.

Figura 1: Composição dos custos que envolvem a produção de Café.
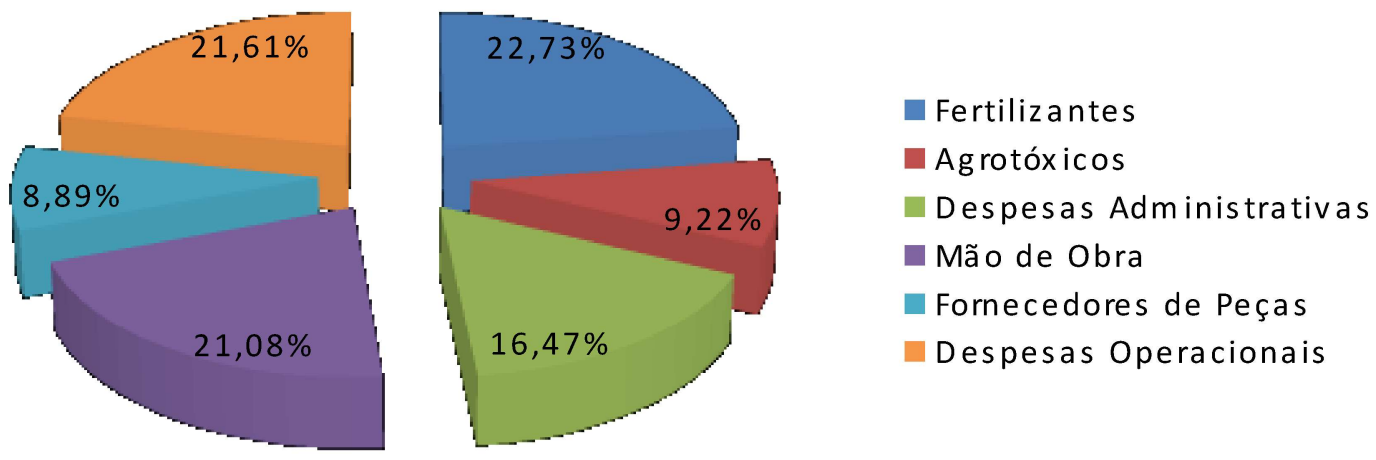

Fonte: Dados da pesquisa (2020)

Nota: Com uma média anual de 42 sacas por hectare e utiliza a mecanização para efetuar a colheita, preparo da terra, adubações e pulverizações. 
Como determinado pelo agrônomo da fazenda a produção cafeeira terá uma produtividade por um tempo de 20 anos, apresentando uma depreciação anual de $5 \%$, as variáveis dos custos que envolvem a cultura do café precisam ser analisadas e controladas com muito cuidado para que o produtor consiga obter uma rentabilidade satisfatória para realização de mais investimentos de expansão e realização de melhorias na localidade. A cultura sofre várias influências de fatores incontroláveis, como os ambientais, os fisiológicos, os tratos culturais além dos mercados que são muito voláteis.

As formas de aplicações das técnicas de análise de investimentos fornecem ao produtor informações de elevada importância sobre a viabilidade econômico-financeira do projeto a ser investido, assim auxiliando na tomada decisão que é um fator de muita importância.

Para estudo da viabilidade foi considerado um investimento realizado em um conjunto de maquinário novo, para melhor seleção do café que será coletado do chão, assim considerando que proporcionará um retorno de $\mathrm{R} \$ 209.600,00$ por ano em cima do investimento realizado, o preço da saca de café considerada foi de $\mathrm{R} \$ 450,00$.

$\mathrm{Na}$ Tabela 2 são apresentados os resultados do Valor Presente Líquido (VPL), Taxa Interna de Retorno (TIR), Payback Descontado (PBD) e o Custo/Benefício (B/C).

Tabela 2: Resultados das técnicas de avaliação da viabilidade econômico-financeira.

\begin{tabular}{c|c}
\hline Indicadores & Valores \\
\hline Valor Presente Líquido - VPL (R\$) & $\mathrm{R} \$ 22.523,10$ \\
\hline Taxa Interna de Retorno - TIR (\%) & $17,97 \%$ \\
\hline Payback Descontado - PBD (Anos) & 7 anos \\
\hline Custo/Benefício - B/C (R\$) & R\$ 1,02 \\
\hline
\end{tabular}

Fonte: Dados da pesquisa (2020)

Nota: Resultados considerados com o preço real da saca de café a $R \$ 450,00$.

Com relação ao (VPL) o valor obtido foi de R\$22.523,10, sendo maior que zero. Assim, esse investimento na atividade cafeeira demostra ser viável à taxa de desconto de $17 \%$ ao ano, a taxa foi utilizada baseada no retorno esperado pelo produtor, calculada em cima do valor investido de $\mathrm{R} \$ 800.000,00$, isso significa que o capital investido foi remunerado a uma taxa de $17 \%$ ao ano, depois de realizado o cálculo, elevando a riqueza do produtor com cerca de $\mathrm{R} \$ 22.523,10$, no sétimo ano em que o (VPL) se mostra positivo.

Os resultados da (TIR), que representa a taxa interna de retorno do investimento que foi realizado e que acaba igualando o (VPL) a zero, foi de $17,97 \%$, assim sendo maior que a taxa que foi requerida de $17 \%$ ao ano, dessa forma demostra a viabilidade do investimento. Desse modo, o investimento realizado é viável até a taxa de desconto de $17,97 \%$. Se caso houver outros investimentos alternativos que pode proporcionará uma remuneração maior desse capital que a (TIR) apresenta, então o investimento alternativo será melhor do que o que foi realizado.

Para o período de recuperação do investimento foi utilizado a taxa de $17 \%$ ao ano, obtendo assim o Payback Descontado (PBD), dessa forma o PBD ocorre em 7 anos, mas se for considerado em meses a recuperação ocorrerá em 6 anos e 2 meses.

Como pode ser visto na tabela 2 o índice custo-benefício $(\mathrm{B} / \mathrm{C})$ demostra a viabilidade para a empresa, o índice indica $1,02>1$, assim considerando a viabilidade do investimento conforme explica Samanez (2010).

\subsection{Análise de Cenários}

A análise de cenários será utilizada para simular situações futuras da produção e dos custos que serão esperados pelo produtor na melhor das hipóteses ou na pior das hipóteses e para avaliar quais são os impactos que serão causados por alteração das diversas variáveis nos resultados que são esperados pelo produtor, auxiliando o produtor nas tomadas de decisões futuras, sobre financiamento e custeio da produção. 
De acordo com Lapponi (2007) é proposto três tipos de análise de cenários, o esperado, o otimista e o pessimista. Correia Neto (2009) relata que estes cenários são os que são mais usados constantemente e orienta que o cenário esperado normalmente é o considerado como base para a realização dos levantamentos dos demais cenários. O cenário pessimista as variáveis dos custos e das receitas que serão obtidas terão influências negativas no fluxo de caixa e levando a um resultado inferior que leva a considerar que o investimento que foi realizado na cultura do café foi desfavorável, no cenário otimista são considerados as mudanças favoráveis nas variedades do fluxo de caixa, em relação a entradas mais altas e saídas mais baixas dos valores.

\subsection{Cenários esperados 2017/2018}

Os custos estimados para o cenário esperado para a safra 2017/2018 foram baseados em uma produtividade média de 50 sacas por hectare. Observa-se que os fertilizantes representam R\$ $2.664,09$ dos custos por hectares, seguido pelo custo dos agrotóxicos que apresenta $\mathrm{R} \$ 1.073,80$ por hectare, as despesas administrativas ficaram com um custo de $\mathrm{R} \$ 1.936,00$ por hectare, os custos com mão de obra ficaram apresentados em R\$2.087,76 por hectare, as despesas com os fornecedores de peças ficaram com $\mathrm{R} \$ 1.422,50$ por hectare, as despesas fixadas para o processo da colheita mecanizada preparo do solo, adubações ficaram com um custo de $\mathrm{R} \$ 2.424,17$ por hectares, o preço da saca de $60 \mathrm{~kg}$ do café foi considerada a da comercialização de Patrocínio em Minas Gerais, por ser o local para onde a fazenda mais comercializa o café atualmente, sendo o preço atual é $\mathrm{R} \$ 450,00$. No cenário esperado o custo total da produção ficará em $\mathrm{R} \$ 1.056 .357,12$, no que totalizará em um custo por hectare de $\mathrm{R} \$ 11.608,32$, com a comercialização da produção que ficou estabelecida em 50 sacas por hectare, terá fluxo de caixa para cobrir os custos da produção e ficará com um saldo líquido de R\$991.142,88. Para uma melhor identificação na Tabela 3 é apresentado cada custo com seu valor total por hectare.

Tabela 3: Descrição dos custos envolvidos para o cenário esperado.

\begin{tabular}{c|c|c}
\hline Descrição & Custo/Ha & Valor total \\
\hline Fertilizantes & $\mathrm{R} \$ 2.664,09$ & $\mathrm{R} \$ 242.432,19$ \\
\hline Agrotóxicos & $\mathrm{R} \$ 1.073,80$ & $\mathrm{R} \$ 97.715,80$ \\
\hline Despesas Administrativas & $\mathrm{R} \$ 1.936,00$ & $\mathrm{R} \$ 176.176,00$ \\
\hline Mão de Obra & $\mathrm{R} \$ 2.087,76$ & $\mathrm{R} \$ 189.986,16$ \\
\hline Fornecedores de Peças & $\mathrm{R} \$ 1.422,50$ & $\mathrm{R} \$ 129.447,50$ \\
\hline Custos Operacionais & $\mathrm{R} \$ 2.424,17$ & $\mathrm{R} \$ 220.559,47$ \\
\hline Custo Total & $\mathrm{R} \$ 11.608,32$ & $\mathrm{R} \$ 1.056 .357,12$ \\
\hline
\end{tabular}

Fonte: Dados da pesquisa (2020)

Na Figura 2 é apresentada a porcentagem do custo total de cada item mencionado. 
Figura 2: Estimativa de custos realizada para a análise do cenário que é esperada para a safra 2017/2018.
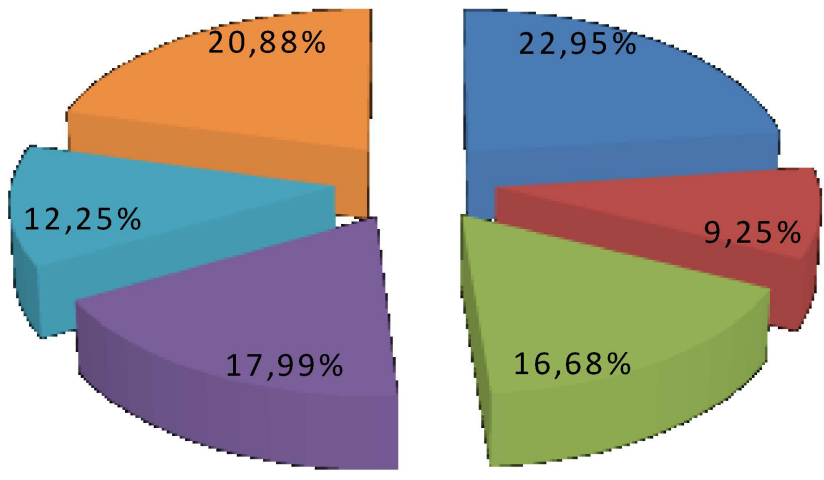

\author{
Fertilizantes \\ Agrotóxicos \\ Despesas Administrativas \\ Mão de obra \\ Fornecedores de peças \\ Custos Operacionais
}

Fonte: Dados da pesquisa (2020)

Os resultados ilustrados na Figura 2 são considerados o esperado para o levantamento dos cenários futuros, com relação ao preço do café que influencia em toda tomada de decisão em continuação dos investimentos realizados na cultura, tendo em vista que diversos fatores podem influenciar nos valores previstos. Para tanto foi proposto diferentes cenários com o risco de probabilidade de aumento para os fatores propostos pelo motivo da influência da inflação ou pelo fator da demanda que é um fator imprevisível de se controlar e de se saber em que época a demanda será maior pelos fatores biológicos que influencia nos tratos culturais e tratamentos de pragas, como pode ser visto na Tabela 4.

Tabela 4: Proposta de cenários diferentes ao esperado.

\begin{tabular}{c|c|c|c}
\hline Descrição & Péssimo & Esperado & Ótimo \\
\hline Fertilizantes & $+10 \%$ & Referência & $-10 \%$ \\
\hline Agrotóxicos & $+10 \%$ & Referência & $-5 \%$ \\
\hline Despesas Operacionais & $+9 \%$ & Referência & $-9 \%$ \\
\hline Cotação & $-10 \%$ & $\mathrm{R} \$ 450,00$ & $+10 \%$ \\
\hline Produtividade & 26 sacas $/ \mathrm{Ha}$ & 50 sacas $/ \mathrm{Ha}$ & $65 \mathrm{sacas} / \mathrm{Ha}$ \\
\hline
\end{tabular}

Fonte: Dados da pesquisa (2020)

O aumento ou a redução dos custos dos fertilizantes, agrotóxicos, despesas operacionais, cotações e a produtividade e levada em consideração ao cenário esperado.

\title{
5.2.1 Cenário Péssimo
}

Os custos estimados para o cenário péssimo para a safra 2017/2018 foram considerados a uma produtividade de 26 sacas por hectare devido à ocorrência de fatores incontroláveis. Foi considerado um aumento de $10 \%$ nos fertilizantes, $10 \%$ nos agrotóxicos, nas despesas operacionais o aumento considerado foi de $9 \%$, considerando uma queda expressiva no preço da saca de café de $10 \%$, com isso impactando bastante no resultado do que o produtor terá quando encerrar a produção e a comercialização do café.

$\mathrm{Na}$ Figura 3 é possível observar os pontos onde tiveram aumento, que impactará no resultado obtido pelo produtor. 
Figura 3: Estimativa de custos realizada para análise do cenário péssimo da safra 2017/2018.
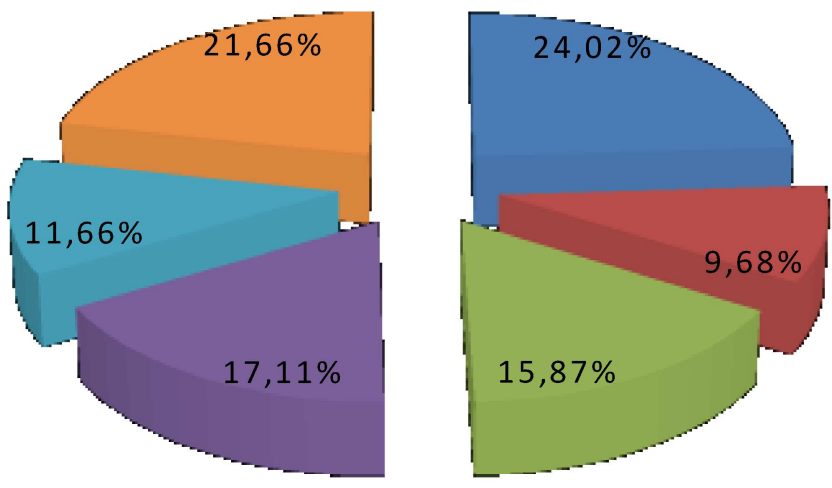

Fertilizantes

Agrotóxicos

Despesas Administrativas

Mão de obra

Fornecedores de peças

Custos Operacionais

Fonte: Dados da pesquisa (2020)

Para a comercialização da saca de café com essa redução de $10 \%$ no preço, e com uma produtividade muito fraca de 26 sacas por hectare, seu fluxo de caixa se apresentará fraco para cobrir os custos da produção, e ficará com déficit de $\mathrm{R} \$ 151.994,57$, como pode ser observado na Tabela 5.

Tabela 5: Descrição dos custos envolvidos para o cenário péssimo.

\begin{tabular}{c|c|c}
\hline Descrição & Custo/Há & Valor total \\
\hline Fertilizantes & $\mathrm{R} \$ 2.930,49$ & $\mathrm{R} \$ 266.674,59$ \\
\hline Agrotóxicos & $\mathrm{R} \$ 1.181,18$ & $\mathrm{R} \$ 107.487,38$ \\
\hline Despesas Administrativas & $\mathrm{R} \$ 1.936,00$ & $\mathrm{R} \$ 176.176,00$ \\
\hline Mão de Obra & $\mathrm{R} \$ 2.087,76$ & $\mathrm{R} \$ 189.986,16$ \\
\hline Fornecedores de Peças & $\mathrm{R} \$ 1.422,50$ & $\mathrm{R} \$ 129.447,50$ \\
\hline Custos Operacionais & $\mathrm{R} \$ 2.642,34$ & $\mathrm{R} \$ 240.452,94$ \\
\hline Custo Total & $\mathrm{R} \$ 12.200,27$ & $\mathrm{R} \$ 1.110 .224,57$
\end{tabular}

Fonte: Dados da pesquisa (2020)

A receita total esperada para o cenário é de $\mathrm{R} \$ 958.230,00$ assim não cobrindo os custos, deste modo fica destacado que apesar do déficit de R $\$ 151.994,57$ no decorrer dos próximos anos se não ocorrer nenhuma eventualidade os valores líquidos que ficarem em caixa após descontar os custos da produção, certa porcentagem pode ser direcionado para cobrir o déficit passado, mesmo com essa característica do investimento estar no vermelho nesse período o projeto ainda sim é caracterizado como viável por ser de rápida recuperação em um único período em que ocorrer safra alta e os preços das sacas se estabilizarem em um percentual favorável aos produtores.

\subsubsection{Cenário Ótimo}

Os custos estimados para o cenário ótimo para a safra 2017/2018 foram considerados com uma produtividade de 65 sacas de café por hectare, considerando uma redução dos custos com os fertilizantes de $10 \%$, dos agrotóxicos de $5 \%$ e das despesas operacionais de $9 \%$. Para o preço da saca de café foi considerado um aumento de $10 \%$, com isso fazendo com que o café seja mais valorizado e o retorno adquirido seja mais satisfatório por ter ocorrido baixas em alguns custos que impactam na produção cafeeira, na Figura 4 é possível observar o percentual estabelecido entres os custos da produção. 
Figura 4: Estimativa de custo realizada para análise do cenário ótimo da safra 2017/2018.

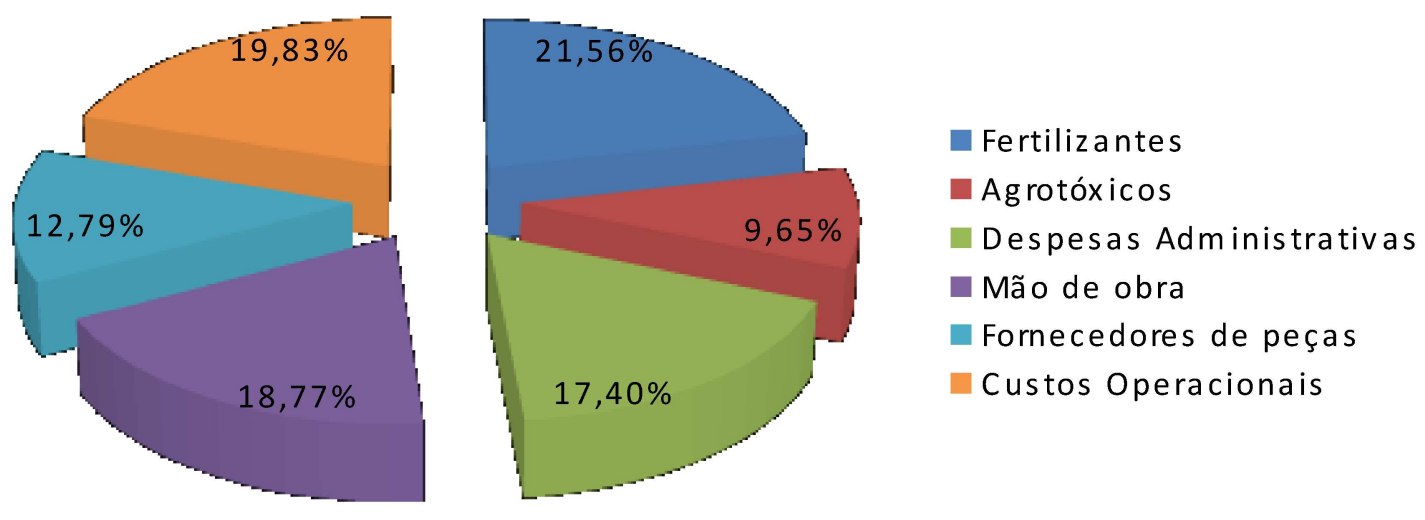

Fonte: Dados da pesquisa (2020)

Como apresentado no cenário ótimo, os custos não impactaram tanto. O custo total da produção ficou estabelecido em $\mathrm{R} \$ 1.012 .223,03$, e o preço do café sofre um acréscimo satisfatório, assim acaba influenciando a comercialização, por também ter ocorrido uma boa produtividade sem ter que haver tantos tratamentos em função das pragas.

Tabela 6: Descrição dos custos envolvidos para o cenário ótimo.

\begin{tabular}{c|c|c}
\hline Descrição & Custo/Ha & Valor total \\
\hline Fertilizantes & $\mathrm{R} \$ 2.397,68$ & $\mathrm{R} \$ 218.188,88$ \\
\hline Agrotóxicos & $\mathrm{R} \$ 1.073,80$ & $\mathrm{R} \$ 97.715,80$ \\
\hline Despesas Administrativas & $\mathrm{R} \$ 1.936,00$ & $\mathrm{R} \$ 176.176,00$ \\
\hline Mão de Obra & $\mathrm{R} \$ 2.087,76$ & $\mathrm{R} \$ 189.986,16$ \\
\hline Fornecedores de Peças & $\mathrm{R} \$ 1.422,50$ & $\mathrm{R} \$ 129.447,50$ \\
\hline Custos Operacionais & $\mathrm{R} \$ 2.205,59$ & $\mathrm{R} \$ 200.708,69$ \\
\hline Custo Total & $\mathrm{R} \$ 11.123,33$ & $\mathrm{R} \$ 1.012 .223,03$ \\
\hline
\end{tabular}

Fonte: Dados da pesquisa (2020)

Com esse resultado satisfatório da produtividade, foi possível manter um fluxo de caixa positivo após a comercialização da saca de café com o aumento ocorrido, somando uma receita esperada para o cenário de $\mathrm{R} \$ 2.927 .925,00$ dessa forma ficou com um lucro líquido de $\mathrm{R} \$$ 1.915.701,97, em caixa. Com isso possibilitando possíveis investimentos em fatores que proporcionariam aumento da produção e até mesmo a expansão de novas áreas a serem cultivadas, sendo assim nesse cenário caracteriza-se como viável.

\section{Considerações Finais}

Neste presente estudo foi possível aplicar conceitos sobre os tipos de custos, sobre os fatores de viabilidade e a importância de se ter conhecimento da viabilidade de um empreendimento. Nesse contexto foi possível atender ao objetivo geral do presente estudo é analisar a viabilidade econômico-financeira de um empreendimento de produção e venda de café, para expansão da atividade na região Noroeste de Minas Gerais.

Os objetivos específicos propostos foram atingidos através de entrevistas e análises de documentos que foram realizadas para levantamento dos gastos ocorridas no empreendimento da safra 2016/2017, após o comprimento desses objetivos foi possível fazer a análise dos indicadores de viabilidade econômico-financeira sendo Valor Presente Líquido (VPL) R\$ 22.523,10, Taxa Interna de Retorno (TIR) 17,97\%, Payback Descontado (PBD) 7 anos e Razão Custo/Benefício (C/B) R \$ 1,02. Assim considerando o preço da saca de café de $\mathrm{R} \$ 450,00$, dessa forma investimento 
realizado proporcionará uma coleta de 400 sacas de café a mais, assim demostrando que o sistema de produção adotado se apresenta como economicamente viável.

Por fim, foram propostos novos cenários para as próximas safras que irão ocorrer, através dos cenários foi levantado o ótimo e o péssimo com fatores determinantes como aumento dos custos, queda dos preços de comercialização e da produtividade que foi imposta entre os cenários. Nos cenários ótimos e nos esperados pelo produtor. Os resultados são positivos em função da produtividade e em relação ao fator preço dos insumos e para comercialização o preço da saca de café colabora para esses resultados positivos. Nos cenários inviáveis os fatores determinantes são em primeiro lugar a produtividade baixa e o preço de comercialização que é estagnado baixo para o mercado assim não favorecendo o produtor rural.

Pode se concluir que os fatores que influenciam a expansão da cafeicultura na Região Noroeste de Minas Gerais é a sua viabilidade econômico-financeira, e um dos fatores que o produtor tem que ficar bastante atento é sobre o preço de comercialização e sobre as melhores formas de otimizar os custos de produção e produtividade da cultura. $\mathrm{O}$ empresário rural deve efetuar uma forma que vise priorizar o gerenciamento e o planejamento dos recursos, buscando uma melhor otimização da produção e minimizar os custos o máximo possível, não perdendo o foco na comercialização para aproveitar preço e mercado. Conforme demonstrado na pesquisa, em cenários desfavoráveis, o controle dos custos de produção, e também das vendas responsável pela cobertura destes custos, requerem bastante atenção, principalmente porque o preço da saca de café e muito volátil ao longo do ano.

Para realização deste trabalho pode ser destacado como limitação ao acesso as informações financeiras confidenciais da propriedade assim como o deslocamento até o escritório da empresa para levantamento dos dados e realização.

Contudo este estudo pode servir como base para novas pesquisas sobre a saúde financeira das organizações e para mensurações de produtividade assim como os custos que estão envolvidos no setor de produção de empresas do segmento cafeeiro. Ressaltando também que os resultados poderão auxiliar os produtores rurais nas tomadas de decisões como, redução de custos, otimização da produtividade, do setor de produção e, também, nas tomadas de decisões sobre possíveis investimentos com a finalidade de se obter melhoramentos operacionais.

Para possíveis trabalhos futuros, é sugerido novas aplicações de modelos de viabilidade econômico-financeira assim como novos modelos de análise de cenários, com determinantes de probabilidades que cada cenário tem de ocorrer.

\section{Referências}

ABIC - Associação Brasileira da Indústria de Café. (2016). Desempenho da produção e do Consumo Interno. Disponível em: $<$ http://www.abic.com.br/publique/cgi/cgilua.exe/sys/start.htm?sid=61\#expect2.2015.2 $>$. Acessado em 26 de junho de 2017.

Azevedo, P. F. (2001). Comercialização de produtos agroindustriais. In: BATALHA, M, O.

(Coord.). Gestão agroindustrial. São Paulo: Atlas, p. 64-98.

Bruni, A. L., \& Famá, R. (2003). As decisões de investimento. São Paulo: Atlas.

CECAFÉ - Conselho dos Exportadores de Café do Brasil. (2016). Relatório mensal Dezembro. Disponível em:

$<$ http://www.sapc.embrapa.br/arquivos/consorcio/informe_estatistico/CECAFE_Relatorio_Mens al DEZEMBRO2 2016.pdf $>$. Acessado em: 10 de junho de 2017.

CEPEA - Centro de Estudos Avançados em Economia Aplicada da Esalq/USP. (2016a). Relatório PIB Agro - Brasil, Disponível em: $<$ http://www.cepea.esalq.usp.br/upload/kceditor/files/Relatorio\%20PIBAGRO\%20Brasil_DEZE MBRO.pdf>. Acessado em: 24 de Junho de 2017. 
CEPEA - Centro de Estudos Avançados em Economia Aplicada da Esalq/USP. (2016b). Índices Exportações do Agronegócio. Disponível em:

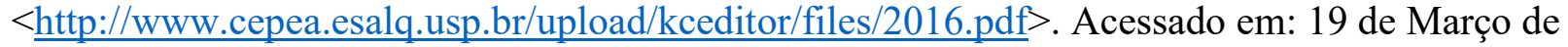
2017.

Crepaldi, S. A. (2002). Contabilidade Gerencial: Teoria e Prática. 2 ed. São Paulo, Atlas.

Crepaldi, S. A. (2011). Contabilidade Rural: Uma Abordagem Decisorial. 6 ed. São Paulo, Atlas.

CONAB - Companhia Nacional de Abastecimento. Acompanhamento da Safra Brasileira de Café. (2016). V.3 - SAFRA 2016 - N.4 - Quarto Levantamento/ Dezembro 2016. Disponível em:

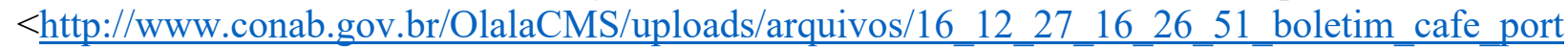
ugues - 4o lev - dez.pdf > Acessado em: 02 de Abril de 2017.

CONAB - Companhia Nacional de Abastecimento. Acompanhamento da Safra Brasileira de Café. (2017). V.4 Safra 2017 - N.2 - Segundo Levantamento/MAIO 2017. Disponível em:

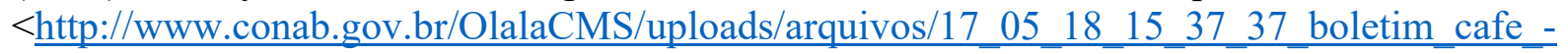
_maio_2017.pdf>. Acessado em; 18 de março. 2017.

Correia Neto, J. F. (2009). Elaboração e avaliação de projetos de investimento: Considerando o risco. Rio de Janeiro: Elsevier.

EPAMIG - Empresa de Pesquisa Agropecuária de Minas Gerais. (2016). Balanço Social 2016 EPAMIG. Disponível em: $<\underline{\text { http: } / / \text { www.epamig.br/index.php?option }=\text { com_content\&task }=\text { view\&id }=2246>}$. Acessado em 11 de Março de 2017.

Kimura, H. (1998). Administração de riscos em empresas agropecuárias e agroindustriais. Caderno de Pesquisa em Administração, 1(7), p. 50-61.

Lapponi, J. C. (2007). Projetos de investimento na empresa. Rio de Janeiro: Elsevier.

MAPA - Ministério da Agricultura Pecuária e Abastecimento. (2016). Informe Estatístico do Café Outubro de 2016. Disponível em: $<$ http://www.agricultura.gov.br/agroestatisticas/cafe/informeestatistico-cafe-outubro-2016.xlsx/view>. Acessado em: 19 de Junho de 2017.

Marconi, M. A., \& Lakatos E. M. (2011). Técnicas de pesquisa: Planejamento de pesquisa, amostragens e técnicas de pesquisa, elaboração, análise e interpretação de dados. 7 ed. São Paulo; Atlas.

Marion, J. C. (2010). Contabilidade Rural: Contabilidade Rural, Contabilidade da pecuária, Imposto de Renda, Pessoa Jurídica. 12 ed. São Paulo, Atlas.

Minayo, M. C. e S. (2011). Pesquisa Social: Teoria, método e criatividade. 30 ed. Petrópolis, RJ: Vozes.

Padoveze, C. L. (2010). Contabilidade gerencial: um enfoque em sistema de informação contábil. 7 ed. São Paulo: Atlas.

Sá, A. L. (2000). Fundamentos da contabilidade geral. Belo Horizonte. Uma editora.

Samanez, C. P. (2010). Matemática financeira. 5 ed. São Paulo, Pearson Prentice Hall.

Santos, G. J., Marion, J. C., \& Segatti, S. (2009). Administração de Custos na Agropecuária. 4 ed. São Paulo, Atlas. 


\title{
Economic and Financial viability for expansion of coffee culture in Unaí, Minas Gerais
}

\begin{abstract}
The coffee is of extreme importance in the economic sphere and in society with the generation of thousands of jobs and income in Brazil. Minas Gerais is the largest producer of coffee from Brazil. In this way the coffee production is an activity aggregation of economic value in the state. In this context, the objective of this study was to investigate what financial factors influence the expansion of coffee growing in the Northwest region of Minas Gerais. In this way were used some techniques of indicators for analysis of projects which seek to identify the feasibility of investments made in this culture. The sector of coffee production is responsible for generation of thousands of jobs in Brazil, especially for Minas Gerais for being the largest producer and exporter of this commodity. In relation to the methodology used, this work had as a nature documentary research, field, bibliographical, exploratory, quantitative-qualitative. We sought to measure the expenditure already incurred in undertaking in the season 2016/2017, analyze the net present value, internal rate of return, the discounted payback period and also the cost/benefit of an investment made to better reap the maker of the ground, besides carrying out estimates of future scenarios for the company's productivity. With the results obtained, it was possible to carry out the analysis of economic and financial viability of the project on the investment, which was economically viable.
\end{abstract}

Keywords: Coffee; Economic viability; Investment; Financial control.

\section{Sobre os Autores}

\section{Douglas Fonseca dos SANTOS}

Bacharel em Administração pela Faculdade CNEC Unaí (MG). Rua Celina Lisboa Frederico, 142, Centro, Unaí, MG, Brasil, CEP 38610-041.

E-mail: douglasfsadm@,hotmail.com.

\section{Gevair CAMPOS}

Professor no curso de Administração da Faculdade CNEC Unaí (MG). Mestre em Agronegócios pela Universidade de Brasília (UnB). Rua Celina Lisboa Frederico, 142, Centro, Unaí, MG, Brasil, CEP 38610-041.

E-mail: javas1989@gmail.com. 